\title{
CLINICAL MANIFESTATIONS AND BURDEN OF HPV INFECTION - PREVENTION AND THERAPEUTIC POSSIBILITIES
}

\section{Ana-Maria CIOTI ${ }^{1}$, Ana Maria A. STANESCU ${ }^{2}$, loana V. GRAJDEANU ${ }^{2}$, Daniela MIRICESCU ${ }^{3}$, Bogdan SERBAN ${ }^{2,4}$, Ovidiu G. BRATU ${ }^{2,5}$, Camelia C. DIACONU 2,6}

${ }^{1}$ CMI „Dr. Grajdeanu Ioana Veronica“ Bucharest, Romania

${ }^{2}$ University of Medicine and Pharmacy „Carol Davila“, Bucharest, Romania

${ }^{3}$ Discipline of Biochemistry, Faculty of Dental Medicine, „Carol Davila“ University of Medicine and Pharmacy Bucharest, Romania

${ }^{4}$ Emergency Universitary Hospital Bucharest, Bucharest, Romania

${ }^{5}$ University Emergency Central Military Hospital, Academy of Romanian Scientists, Bucharest, Romania

${ }^{6}$ Clinical Emergency Hospital of Bucharest, Bucharest, Romania

Received 27 Sept 2019, Accepted 01 Nov 2019

https://doi.org/10.31688/ABMU.2019.54.4.19

\section{Abstract}

Human Papilloma Virus (HPV) is the virus responsible for the most common and widespread sexually-transmitted infection. Most sexually active people will acquire at least one type of HPV in their lifetime and some may be repeatedly infected. In most cases, HPV infection is transient and asymptomatic, but when the infection persists it can cause benign diseases, precancerous lesions and malignancies of various locations. Low risk HPV types can produce proliferative lesions either in the skin or mucosa, whereas high risk types possess carcinogenic potential. This paper is a review of the latest data in the literature regarding the clinical manifestations of HPV infections, current prevention and therapeutic possibilities.

Keywords: HPV infection, carcinogenic potential, anogenital warts.

\section{Résumé}

Manifestations cliniques et fardeau d'une infection à HPV - prévention et possibilités thérapeutiques

Le virus du papillome humain (VPH) est le virus responsable de la plus commune et répandue infection sexuellement transmissible. La plupart des personnes sexuellement actives contracteront au moins un type de VPH au cours de leur vie et certaines pourront être infectées à plusieurs reprises. Dans la plupart des cas, l'infection à HPV est transitoire et asymptomatique, mais si l'infection persiste, elle peut provoquer des maladies bénignes, des lésions précancéreuses et des tumeurs malignes à divers endroits. Les types de HPV à faible risque peuvent produire des lésions prolifératives dans la peau ou les muqueuses, alors que les types à haut risque possèdent un potentiel cancérogène. Cet article passe en revue les dernières données de la littérature concernant les manifestations cliniques des 


\section{Abbreviations}

CDC - Centers for Disease Control and Prevention

CIN - cervical intraepithelial neoplasia

HPV - human papillomavirus

Hsp-E7 - heat shock protein

KTP - potassium titanyl phosphate

$\mathrm{MMC}$ - mitomycin C

MMR - measles-mumps-rubella

PD-L1 - programmed death-ligand 1

POD-NLC - podophyllotoxin-loaded nanostructured

lipid carrier

RRP - recurrent respiratory papillomatosis

VEGF - vascular endothelial growth factor

VLPs - virus-like particles

\section{INTRODUCTION}

Human papillomaviruses (HPVs) are a group of more than 200 small DNA viruses that infect the basal epithelium, 40 of which with tropism for the mucosal epithelium affecting genitalia and the oropharynx. They are classified into two major groups, low-risk and high-risk strains, depending on the ability of the virus to induce malignant transformation. Infection with one type of HPV does not prevent infection with a different type. $5 \%$ to $30 \%$ out of mucosal HPV infections are caused by multiple strains of the virus ${ }^{1-3}$.

According to the Centers for Disease Control and Prevention (CDC), anogenital HPV is the most common sexually-transmitted infection, 8 in 10 sexually active people will be infected in their lifetime with at least one strain of HPV ${ }^{1,2}$. The prevalence of the detectable HPV infection in European women from the general population is estimated to be $14 \%$ and it reaches a peak in the age groups represented by adolescents and women in their early $20 \mathrm{~s}^{3,4}$.

Approximately $90 \%$ of the human papillomavirus infections resolve spontaneously within two years, whereas some high-risk infections persist and are responsible for cancers and precancerous lesions of the vulva, vagina, anus, penis, head and neck, as well as genital warts ${ }^{5}$. The risk factors for persistent infection include multiple sex partners, becoming sexually active at an early age, coinfection with other sexually-transmitted agents (e.g. HIV, Chlamydia trachomatis, HSV2), immunosuppression, tobacco smoking, high parity and long-term hormonal contraceptive use. Condom use offers only partial protection against human papillomavirus infection because exposure to HPV can occur in areas that are not covered or protected by a condom, such as the scrotum or perianal region ${ }^{6}$. infections à HPV, la prévention actuelle et les possibilités thérapeutiques.

Mots-clés: infection à HPV, potentiel cancérogène, verrues anogénitales.

HPV infection occurs through inoculation of the virus into the basal cell layer of stratified squamous epithelial cells, affecting a stem cell or converting an epithelial cell into a stem cell-like. Infection stimulates cellular proliferation in the epithelium, as the cells divide, the viral genome is replicated and inserted into each progeny cell. The infected cells display a variety of changes, from benign hyperplasia to dysplasia to invasive carcinoma ${ }^{7,8}$.

\section{Condyloma acuminatum (Anogenital warts)}

Anogenital warts are a common manifestation of the HPV infection characterized by genital, perineal and perianal hyperplasia'. Several types of human papillomavirus infection have been isolated in genital warts, such as: HPV 2, 6, 11, 40, 42, 43, 54; the most commonly associated strains are HPV6 and HPV11 ${ }^{10}$.

A review in 2013 calculated the global incidence of anogenital warts, that ranged from 160-289 cases per 100,000 person-years (median 194.5 per $100,000)$. The incidence peaked before 24 years of age in females and between 25 and 29 years of age among males ${ }^{11}$. Genital warts can be an economic burden, only in the United States the direct annual medical costs associated with the management of genital HPV infection, including treatment of genital warts, precancers and cancers, and screening for cervical cancer, are estimated to be $\$ 1.7$ billion? .

Anogenital warts are diagnosed by clinical inspection. Biopsy of atypical lesions is indicated when the wart is pigmented, indurated, affixed to underlying tissue, bleeding, or there are ulcerated lesions. Biopsy may also be required in immunocompromised patients when the diagnosis is uncertain, the lesions are non-responsive to standard therapy or they worsen during treatment ${ }^{12}$. 
Table. 1. Management of anogenital warts with grading of recommendation ${ }^{14}$.

Management of Anogenital Warts with Grading of
Recommendation

Anogenital warts present as exophytic fronds or cauliflowerlike growths on anogenital skin or mucous membranes, or both. Anogenital warts are frequently multiple, asymmetric and polymorphic and can occasionally cause bleeding, pruritus and local discharge? Genital warts have a negative effect on the quality of life, can be intractable to treatment, may regenerate spontaneously or remain in remission for a long time. Without proper treatment the lesions can resolve spontaneously, remain unchanged, or increase in size or number ${ }^{13}$.

There is currently no specific antiviral therapy available to cure HPV infection ${ }^{14}$. Most treatments for verrucae involve physical destruction of the infected cells. The choice of treatment depends on the location, number, dimension and type of wart, as well as on the age and cooperation of the patient. Pain, risk of scarring, and the benefit to the patient should be taken into consideration ${ }^{8}$.

Current available therapies for genital warts are presented in Table 1. They most likely reduce, but probably do not eliminate HPV infectivity. It remains unclear if the depletion of HPV viral DNA resulting from treatment reduces future transmission of the virus $^{14}$.

Currently under development is a podophyllotoxin-loaded nanostructured lipid carrier (POD-NLC) for the treatment of condyloma acuminatum. NLCs are able to adhere to the skin surface and transport drugs in a controlled manner and are a promising new delivery system for POD in the treatment of anogenital warts $^{15}$.

\section{RECURRENT RESPIRATORY PAPILLOMATOSIS}

Recurrent respiratory papillomatosis (RRP) is a chronic disease caused by human papillomavirus
(HPV), usually types 6 and 11 that determine abnormal recurrent growth of small, benign tumors, or papillomas, in the respiratory tract affecting both children and adults ${ }^{16}$.

Most RRP lesions affect the larynx, but may also appear in the mouth, trachea, bronchia, lung parenchyma and esophagus. The juvenile-onset form of RRP is more frequent and more aggressive with more severe symptoms, requiring repeated surger$i^{1}{ }^{17}$. It can cause severe voice disturbance, hoarseness, airway obstruction and potentially fatal distal small-airway obstruction leading to post-obstructive pneumonias ${ }^{18}$.

The surgical method for removing airway papillomas is by microdebriders or laser ablation using either KTP (potassium titanyl phosphate) or carbon dioxide lasers. Because the debridements are frequent, the underlying tissue is worn down significantly, frequently with scarring. Pharmacological methods are used to improve the outcome of surgery, by increasing the length of time between operations, or by minimizing recurrence of RRP lesions ${ }^{19}$.

Cidofovir is a broad-spectrum, antiviral drug that inhibits viral DNA polymerases and is used as an adjuvant therapy to surgery. Intralesional injections with Cidofovir are the most common medical treatment for RRP but side effects have been observed such as malignant transformation, nephrotoxicity, cutaneous rash, headache, and vocal cord scarring. Cidofovir can also be administered as systemic treatment or by inhalation ${ }^{16}$.

Studies have shown that anti-reflux medication used in patients with juvenile-onset RRP and gastroesophageal reflux disease slows the growth rate of papillomas. Treatment with Heat shock protein (Hsp-E7) has been shown to prolong the interval between surgeries. In some cases, the measles-mumps-rubella (MMR) vaccine used as adjuvant therapy in RRP induced remission of the disease $\mathrm{s}^{16,20}$.

Avelumab is an FDA-approved anti-PD-L1 (programmed death-ligand 1) monoclonal antibody currently under study that demonstrated safety and clinical activity in patients with laryngeal $\mathrm{RRP}^{18}$.

Bevacizumab is a monoclonal antibody against vascular endothelial growth factor (VEGF) that has a role in RRP development. Systemic bevacizumab appears to have significant promise in the most treatment-resistant and aggressive forms of papillomatosis with a low complication profile. Optimal protocols for treatment should be developed regarding the optimal dosing frequency and duration of therapy for bevacizumab in the treatment of $\mathrm{RRP}^{21,22}$. 


\section{Conjunctival papilloma}

Conjunctival papilloma is an acquired benign squamous cell tumor that can present at any age, but most frequently in the third and fourth decades of life. It may manifest as sessile or pedunculated conjunctival mass, usually with a slow progressive course $^{23,24}$. Inverted papillomas of the conjunctiva are rare benign masses with a greater tendency for malignant transformation into transitional cell carcinoma, squamous cell carcinoma, or mucoepidermoid carcinoma ${ }^{25}$. Papillomas have been associated with HPV infection, usually types 6 and $11^{23,24}$.

The transmission of HPV infection in conjunctival papilloma in adults is considered to be autoinoculation from contaminated fingers to the conjunctiva. A study has documented hand carriage of HPV types in patients with genital warts ${ }^{26}$. Conjunctival papillomas have also been reported in infants due to vertical transmission, when the conjunctiva of the newborn is contaminated by the affected genital $\operatorname{tract}^{27}$.

Conjunctival papillomas may show spontaneous regression in some cases and observation and reevaluation are indicated for small asymptomatic conjunctival lesions. Because of the risks of recurrence and spreading, management of conjunctival papilloma now includes non-surgical treatment options in an effort to provide less invasive, more effective and sustained therapies. Topical chemotherapy and immunotherapy are part of the treatment options for conjunctival papilloma as primary non-invasive treatment or adjuvant treatment combined with surgery ${ }^{23}$.

Topical treatment with IFN is recommended as primary treatment either alone or followed by surgery if necessary, with a dosage of $1 \mathrm{MIU} / \mathrm{ml} 4$ times daily. For lesions situated in a location where prolonged contact with topical medications is difficult intralesional IFN injections are an option with the risk of flu-like symptoms such as myalgias and fever that can be avoided by administering an oral anti-pyretic. As an adjuvant, an injection of 3 MIU of IFN $\alpha-2 b$ at the end of the surgery has proven beneficial ${ }^{23,29}$.

Mitomycin C (MMC) can be used as a topical treatment or as an adjuvant but it has a higher frequency of adverse side effects compared with IFN, the most common being ocular discomfort and pain and conjunctival hyperemia ${ }^{23,30}$.

Cimetidine is an oral histamine $\mathrm{H} 2$ receptor antagonist which at high doses demonstrates immunomodulatory effects evoked by inhibiting suppressor $\mathrm{T}$ cell $\mathrm{H} 2$ receptors and by increasing delayed type hypersensitivity responses. Cimetidine has been used in cases of massive and recurrent conjunctival papillomas as peri-surgical adjuvant therapy but not all patients respond to the treatment.
Photodynamic therapy is a minimally invasive treatment based on photooxidation that leads to destruction of the target tissue through the action of reactive oxygen species ${ }^{31}$. One case of using photodynamic therapy has been reported and it resulted in complete regression of a caruncular papilloma after one session ${ }^{28}$.

For papillomas that require surgical excision, a 'no-touch' technique along with double freeze-thaw cryotherapy and intraoperative MMC or IFN injection to reduce the risk of recurrences are recommended. The recurrence rate of conjunctival papilloma has been reported to range between $3 \%$ and $27 \%{ }^{28,32}$.

\section{Cervical dysplasia}

Approximately 200,000 women in the U.S are diagnosed with a cervical intraepithelial neoplasia, or cervical dysplasia. Lesions associated with cervical dysplasia are usually subclinical and can be detected by Papanicolaou smear test or colposcopy, with or without biopsy of the lesion. Cervical intraepithelial neoplasia (CIN) is a precancerous lesion, that precedes cervical cancer $^{33,34}$. CIN is classified in 3 categories based on the degree of cellular abnormalities, respectively, mild, moderate, and severe dysplasia? ${ }^{7}$. Clinically, the lesion is asymptomatic and may regress spontaneously or progress to invasive cancer over decades ${ }^{35}$. The frequency of spontaneous regression varies, low-grade cervical cellular abnormalities often regress spontaneously without treatment. Moderate dysplasia has a regression rate of $19 \%$ to $40 \%$ over 6 months to 2 years. In rare cases, high-grade CIN may regress without treatment, particularly for women younger than 30 years old and never in patients infected by HPV16 ${ }^{36,37}$.

\section{Cancer}

Out of the 12,7 million new cancers diagnosed annually worldwide, approximately 610.000 could be attributed to high-risk HPV infection ${ }^{38-40}$. Persistent infection with high-risk HPV types (oncogenic), most notably HPV types 16 and 18, can cause cellular changes that may progress to cervical cancer. High-risk HPV types 16, 18, 31, 33, 45, 52, and 58 are responsible for about $90 \%$ of cervical cancers worldwide and have been associated with cancers of the vulva, vagina, anus, penis, and oropharyn $\mathrm{x}^{41.43}$. Nearly 4 out of every 10 cases of cancer associated with HPV infection occur among men and annually over 14,000 men are diagnosed in the U.S. with cancers caused by HPV ${ }^{44,45}$

Each year in Romania there are over 4000 new diagnosed cases of cervical cancer, 53 cases of vulvar cancer, 55 of vaginal cancer, 133 cases of anal cancer in both women and men, 38 cases of penile cancer and 256 cases of oropharyngeal cancer in both 
women and men. Romania has a cervical cancer' incidence three times higher than the EU (34,9 cases per 100,000 women) and the highest mortality rate $(14,2$ deaths per 100,000 women) $)^{6,46}$.

\section{Prevention}

Since 2006, 115 countries and territories have progressively introduced national HPV vaccination programs ${ }^{47}$. Three HPV vaccines are commercially available, the bivalent, quadrivalent, and nonavalent vaccines that contain virus-like particles (VLPs) of high-risk strains HPV 16 or HPV18. The quadrivalent and nonavalent vaccines also contain VLPs from HPVs $6 / 11$. The nonavalent vaccine additionally protects against HPVs 31/33/45/52/5848,49.

For the HPV vaccine to be most effective, the vaccine should be administered before exposure to the virus. CDC recommends vaccination of all children with two doses of the HPV vaccine at ages 11 or 12 . Currently, only 20 countries and 4 territories have gender-neutral HPV vaccination schedules ${ }^{12,45,50}$. CDC also recommends HPV vaccines for both men and women through age 26 with 3 doses (0-2-6 months) ${ }^{12,51}$.

A meta-analysis of 65 studies, that includes data from 60 million individuals and up to 8 years of post-vaccination follow-up, shows overall decrease of $80 \%$ on the prevalence of types HPV16 and HPV18, a decrease of $70 \%$ in anogenital wart diagnoses, and a significant decrease in CIN2+ pre-cancerous lesions. Another observation of the analyzed data is that herd protection effects are achieved through high coverage vaccination within the overall network of male-female sexual relations ${ }^{48,52}$.

Australia has had a national HPV vaccination program since 2007 initially for girls only, that extended to boys in 2013. There has been a continuous reduction, from 2012 to 2018, of the incidence of the juvenile form of RRP associated with the wide coverage of HPV vaccination in the Australian population, suggesting an important reduction of vertical HPV transmission ${ }^{48,53}$

\section{Conclusions}

In conclusion, HPV is a global burden. Persistent infection is associated with numerous cancer cases, making prevention the most important approach to HPV infection ${ }^{54,55}$. The HPV vaccine should be implemented in every national vaccination schedule. To be successful in prevention of HPV infection through vaccination, high coverage rates should be achieved by a school-based delivery program of gender-neutral vaccination and high community acceptance of HPV vaccination as a cancer prevention strategy.

\section{Compliance with Ethics Requirements:}

„The authors declare no conflict of interest regarding this article"

"No funding for this study“

\section{References}

1. Hartwig S, St Guily JL, Dominiak-Felden G, et al. Estimation of the overall burden of cancers, precancerous lesions, and genital warts attributable to 9-valent HPV vaccine types in women and men in Europe. Infect Agent Cancer. 2017;12:19.

2. Hamborsky J, Kroger A, Wolfe S, et al. Centers for Disease Control and Prevention. Epidemiology and Prevention of Vaccine-Preventable Diseases 13th ed. Human Papillomavirus. Supplement. Washington D.C. Public Health Foundation, 2017.

3. Hahn AW, Spach DH. Human Papillomavirus Infection. National STD Curriculum 2018.

4. Bruni L, Diaz M, Castellsagué X, et al. Cervical Human Papillomavirus prevalence in 5 continents: meta-Analysis of 1 million women with normal cytological findings. J Infect Dis. 2010;202(12):1789-1799.

5. World Health Organization (WHO). Human papillomavirus (HPV) and cervical cancer. 2019. Available from: https:// www.who.int/news-room/fact-sheets/detail/human-papillomavirus-(hpv)-and-cervical-cancer

6. Bruni L, Albero G, Serrano B, et al. ICO/IARC Information Centre on HPV and Cancer (HPV Information Centre). Human Papillomavirus and Related Diseases in the World. Summary Report 2019 Available from: https://www.hpvcentre.net/statistics/reports/XWX.pdf

7. Georgescu SR, Mitran CI, Mitran MI, et al. New insights in the pathogenesis of HPV infection and the associated carcinogenic processes: the role of chronic inflammation and oxidative stress. Journal of Immunology Research, 2018, Article ID 5315816

8. Androphy EJ, Lowy DR. Fitzpatrick's Dermatology in General Medicine, $7^{\text {th }}$ Ed. Warts. 2008;(196):914-923.

9. Steben M. Clinical manifestations and diagnosis of HPV-related disease. Journal of Obstretics and Gynaecology Canada. 2007;29(8),S3:S11-S14.

10. Grajdeanu IV, Stanescu AMA, Stefani C, et al. Verucile genitale si vulvovaginita candidozica in timpul sarcinii - actualitati si posibilitati terapeutice. Revista Medicala Romana 2019;LXVI (3):114-117

11. Patel H, Wagner M, Singhal P, et al. Systematic review of the incidence and prevalence of genital warts. BMC Infect Dis 2013;13:39.

12. Centers for Disease Control and Prevention. Sexually Transmitted Diseases Treatment Guidelines, 2015. MMWR Recomm Rep 2015;64(No. RR-3):1-137.

13. Fenton KA, Lowndes CM. Recent trends in the epidemiology of sexually transmitted infections in the European Union. Sex Transm Infect. 2004;80(4):255-263.

14. Bolognia JL, Schaffer JV, Cerroni L. Dermatology $4^{\text {th }}$ Ed 2017. Philadelphia: Elsevier Saunders. Human Papillomaviruses. 2017;(79):1383-1399

15. Gao Y, Han K, Wang Q, et al. Development of podophyllotoxin-loaded nanostructured lipid carriers for the treatment of condyloma acuminatum. Molecular Medicine Reports 2018;17: 6506-6514

16. Kumar N, Preciado D. Airway papillomatosis: new treatments for an old challenge. Front Pediatr 2019;7:383 
17. Correiaa S, Dionísiob J, Duro da Costa J. Recurrent respiratory papillomatosis of the airway: the experience of an endoscopic unit. Pulmonology Journal 2015;21(2):82-89

18. Allen CT, Lee S, Norberg SM, et al. Safety and clinical activity of PD-L1 blockade in patients with aggressive recurrent respiratory papillomatosis. Journal for Immunotherapy of Cancer 2019;7:119

19. Rogers DJ, Ojha S, Maurer R, et al. Use of adjuvant intralesional bevacizumab for aggressive respiratory papillomatosis in children. JAMA Otolaryngol Head Neck Surg. 2013;139:496-501

20. Derkay CS, Smith RJ, McClay J, et al. HspE7 treatment of pediatric recurrent respiratory papillomatosis: final results of an open-label trial. Ann Otol Rhinol Laryngol. 2005; 114:730-737

21. Rahbar R, Vargas SO, Folkman J, et al. Role of vascular endothelial growth factor-a in recurrent respiratory papillomatosis. Ann Otol Rhinol Laryngol. 2005;114:289-95.

22. Best SR, Mohr M, Zur KB. Systemic bevacizumab for recurrent respiratory papillomatosis: A national survey. The Laryngoscope. 2017;127(10):2225-2229

23. Theotoka D, Morkin MI, Galor A, et al. Update on diagnosis and management of conjunctival papilloma. Eye and Vision 2019;6:18

24. Huang YM, Huang YY, Yang HY, et al. Conjunctival papil loma: Clinical features, outcome, and factors related to recurrence. Taiwan J Ophthalmol. 2018;8(1):15-18

25. Jakobiec FA, Harrison W, Aronian D. Inverted mucoepidermoid papillomas of the epibulbar conjunctiva. Ophthalmology. 1987;94(3):283-287.

26. Sonnex C, Strauss S, Gray JJ. Detection of human papillomavirus DNA on the fingers of patients with genital warts. Sex Transm Infect. 1999;75(5):317-319

27. Kalogeropoulos C, Koumpoulis I, Papadiotis E, et al. Squamous cell papilloma of the conjunctiva due to human papillomavirus (HPV): presentation of two cases and review of literature. Clinical Ophthalmology 2012;6:1553-1561

28. Kaliki S, Arepalli S, Shields CL, et al. Conjunctival papilloma: features and outcomes based on age at initial examination. JAMA Ophthalmol. 2013;131(5):585-593

29. Karp CL, Galor A, Chhabra S, et al. Subconjunctival/ perilesional recombinant interferon $\alpha 2 b$ for ocular sur face squamous neoplasia: a 10-year review. Ophthalmology. 2010;117(12):2241-2246

30. Rubinfeld RS, Pfister RR, Stein RM, et al. Serious complications of topical mitomycin-C after pterygium surgery. Ophthalmology. 1992;99(11):1647-1654

31. Henderson BW, Dougherty TJ. How does photodynamic therapy work? Photochem Photobiol. 1992;55(1):145-157.

32. Tehrani S, Fraunfelder FW. Cryotherapy in ophthalmology. Open J Ophthalmol. 2013;3(4):103-117

33. Hahn AW, Spach DH. Human Papillomavirus Infection. National STD Curriculum 2018 Available from: https:// www.std.uw.edu/go/pathogen-based/hpv/core-concept/all

34. Cozma CN, Raducu L, Avino A, et al. A rare case of vulvar squamos cell carcinoma; case presentation. Journal of Clinical and Investigative Surgery, 2018;3(1):32-36.

35. Massad LS, Einstein MH, Huh WK, et al. 2012 updated consensus guidelines for the management of abnormal cervical cancer screening tests and cancer precursors. Obstetrics $\mathbb{E}$ Gynecology 2013;121(4):829-846

36. Castle PE, Schiffman M, Wheeler CM, et al. Evidence for frequent regression of cervical intraepithelial neoplasia-grade 2. Obstetrics $\mathcal{E}$ Gynecology. 2009;113:18-25
37. Motamedi M, Böhmer G, Neumann HH, et al. CIN III lesions and regression: retrospective analysis of 635 cases. BMC Infect Dis. 2015;15:541

38. Forman D, de Martei C, Lacey CJ, et al. Global burden of human papillomavirus and related diseases. Vaccine 2012;30(S5):F12-23

39. Bratu OG, Marcu RD, Socea B, et al. Immunohistochemistry particularities of retroperitoneal tumors. Rev Chim (Bucharest) 2018;69(7):1813-1816.

40. Diaconu CC, Arsene D, Balaceanu A, Bartos D. A rare tumor revealed by abdominal trauma: case presentation. Romanian Journal of Morphology and Embryology 2014;55(3):973-976.

41. National Institutes of Health, National Cancer Institute. Gardasil 9 Vaccine Protects against Additional HPV Types. Available from: https://www.cancer.gov/types/cervical/research/gardasil9-prevents-more-hpv-types

42. Saraiya M, Unger ER, Thompson TD, et al. US assessment of HPV types in cancers: implications for current and 9-valent HPV vaccines. J Natl Cancer Inst. 2015; 107(6):djv086

43. Diaconu C, Balaceanu A, Morosan E. Sepsis biomarkers: past, present and future. Farmacia 2015;63(6):811-815.

44. Hariri S, Johnson ML, Bennett NM, et al. Population-based trends in high-grade cervical lesions in the early human papillomavirus vaccine era in the United States. Cancer. 2015;121: 2775-2781.

45. Spinu D, Bratu O, Oprea I, Marcu D, Mischianu D. Human papilloma virus infection in men -topographical and procedural aspects - a systematic review. Revista Romana de Urologie, 2016;15(4): 23-27.

46. Spinu DA, Mischianu D, Marcu DR, et al. HPV and Buschke-Lowenstein disease. Research and Science Today 2019; Supliment(2):172-181.

47. Maier C, Bratila E, Bratu OG, Mehedintu C, Criveanu M. HPV vaccination programmes: how efficient and safe? Research and Science Today, 2019;Suppl. 2:72-81.

48. De Sanjose S, Brotons M, La Montagne DS, et al. Human papillomavirus vaccine disease impact beyond expectations. Current Opinion in Virology 2019;39:16-22

49. Cox JT, Palefsky JM. Human Papillomavirus Vaccinations; 2019 UpToDate: Waltham, MA, USA. Available from: https://www.uptodate.com/contents/human-papillomavirus-vaccination

50. Stanescu AMA, Grajdeanu IV, Bejan GC, et al. Prediction of HIV prevalence until 2022 in Romania and the European Union. Romanian Medical Journal, 2018;LXV(4):261-265.

51. Spinu D, Bratu O, Marcu D, et al. HPV and bladder cancer-is there a connection? Modern Medicine. 2017;24(1):1-4.

52. Drolet M, Bénard E, Perez N, et al. Population-level impact and herd effects following the introduction of human papillomavirus vaccination programmes: updated systematic review and meta-analysis. The Lancet 2019;394(10197):497-509.

53. Patel C, Brotherton JM, Pillsbury A, et al. The impact of 10 years of human papillomavirus (HPV) vaccination in Australia: what additional disease burden will a nonavalent vaccine prevent? Euro Surveill. 2018;23(41):1700737.

54. Bodean $\mathrm{O}$, Bratu $\mathrm{O}$, Munteanu $\mathrm{O}$, et al. Iatrogenic injury of the low urinary tract in women undergoing pelvic surgical interventions. Arch Balk Med Union 2018;53(2):281-284.

55. Diaconu C, Balaceanu A, Bartos D. Venous thromboembolism in pregnant woman - a challenge for the clinician. Central European Journal of Medicine 2013;8(5):548-552. 